\title{
NOVA GOVERNAÇÃO PÚBLICA E MERITOCRACIA
}

\author{
João Abreu de Faria Bilhim \\ Centro de Administração e Políticas Públicas, ISCSP-UL, Lisboa, Portugal
}

Resumo É objetivo deste trabalho clarificar, em administração e políticas públicas, o conceito de nova governação pública, distinguindo-o de outras abordagens recentes. Da pesquisa bibliográfica efetuada sobre o "estado da arte", conclui-se que os estudos científicos da governação andam associados à separação entre unidades de provisão e de produção de serviços públicos e a uma nova forma de relação entre o estado e o resto da sociedade (Aligica e Tarko, 2012). Por outro lado, os estudos científicos da governação andam igualmente associados à eficiência das redes de cooperação entre atores sociais e institucionais (Tavares e Mamede, 2011) em que o estado já não desempenha o único nem o principal papel, o que não deixa de marcar a agenda de pesquisa.

Palavras-chave: governação, meritocracia, reforma administrativa.

Abstract The aim of this paper is to clarify, in administration and public policy, the concept of new public governance, distinguishing it from other approaches. The literature search performed on the "state of the art", it is concluded that the scientific studies of governance are associated with the separation of supply and production units of public services and a new form of relationship between the state and the rest of society (Aligica and Tacko, 2012). On the other hand, the scientific studies of governance are also associated with the efficiency of cooperation networks between social and institutional actors (Tavares and Mamede, 2011) in that the state no longer plays the only and not the main role which set the research agenda.

Keywords: governance, meritocracy, administrative reform.

Résumé Ce travail a pour objectif de clarifier, en matière d'administration et de politiques publiques, le concept de nouvelle gouvernance publique, en le distinguant d'autres approches récentes. La recherche bibliographique effectuée sur l'état de l'art permet de conclure que les études scientifiques sur la gouvernance sont associées à la séparation entre unités de provision et de production de services publics et une nouvelle forme de relation entre l'État et le reste de la société (Aligica et Tarko, 2012). Par ailleurs, les études scientifiques sur la gouvernance sont également associées à l'efficacité des réseaux de coopération entre acteurs sociaux et institutionnels (Tavares et Mamede, 2011) où l'État n'est plus seul à jouer le rôle principal, ce qui marque inévitablement l'agenda de la recherche.

Mots-clés: gouvernance, méritocratie, réforme de l'administration.

Resumen El objetivo de este trabajo es aclarar, en administración y políticas públicas, el concepto de nueva gobernanza pública, distinguiéndola de otros enfoques. De la búsqueda bibliográfica realizada en el "estado del arte" se concluye que los estudios científicos del gobierno están asociados con la separación de unidades de producción y suministro de servicios públicos y una nueva forma de relación entre el Estado y el resto de la sociedad (Aligica y Tarko, 2012). Por otro lado, los estudios científicos de la gobernación también están asociados con la eficiencia de redes de cooperación entre agentes sociales e institucionales (Tavares y Mamede, 2011) en que el Estado ya no desempeña el único y no el papel principal, circunstancia que marca la agenda de investigación.

Palabras-clave: gobernanza, meritocracia, reforma administrativa.

\section{Introdução}

Os estudos sobre a governação pública assumem progressiva importância para a administração e políticas públicas desde o início deste século, dadas as consequências 
dos processos de reforma operados no paradigma da Common Law e na Europa Continental nas décadas de 70, 80 e 90 do século passado. Estes processos de reforma foram provocados por um conjunto de fatores, entre os quais se destacam: défices públicos elevados, estagnação económica, retrocessos no estado de bem-estar social, taxas de desemprego elevadas, redução da confiança nas instituições e nos políticos, invasão da liberdade individual pelo estado.

A influência das teorias da escolha pública (TEP) e da nova gestão pública (NGP) conduziu à separação entre unidades de provisão e unidades de produção, cabendo às primeiras fazer as escolhas políticas legitimadas pelo voto, e às segundas produzir bens e prestar serviços públicos. Ora, entre estas unidades inclui-se atualmente uma constelação de organizações e instituições de diferente natureza jurídica: setor púbico empresarial, empresas privadas, organizações do terceiro setor, fundações e instituições públicas e de direito público.

Na perspetiva de Kettl $(2000,2002)$, as reformas, baseadas na nova gestão pública (NGP) ou na reinvenção da governação (RG), procuraram resolver seis problemas: aumentar a produtividade/eficiência, "como fazer mais com menos"; fortalecer as forças de mercado para curar as patologias burocráticas; estreitar os laços entre governo e cidadãos, satisfazendo as suas necessidades pela melhoria do serviço público; descentralizar o poder de decisão na hierarquia burocrática ou em nível político inferior mais próximo do cidadão; melhorar as capacidades do governo para administrar a política pública; responsabilizar os políticos no sentido de darem o que prometeram.

Tais processos de reforma conduziram, desde finais dos anos 80 do século passado, à fragmentação do estado, à sua transformação num estado oco - hollow state (Peters, 1993; Rhodes 1994, 2000) -, à alteração dos processos e da natureza da administração pública, bem como à mudança das funções do estado (Larry, 2005), ao uso de terceiros na prestação de serviços (Milward e Provan, 2000) e na coprodução de serviços públicos (Bovaird, 2007).

Com estas reformas operadas nos últimos 30 anos do século passado, o modelo weberiano perdeu força na administração pública, confrontando-se agora as democracias industrializadas com um estado fragmentado, desregulado, com atribuições de competências externalizadas. À organização única do estado produtor e distribuidor de serviços públicos sucedeu uma constelação de operadores com diferentes naturezas jurídicas e missões. O estado cedeu o seu lugar único e majestático a uma miríade de operadores, de tal forma que, muitas vezes, nem é já o ator mais importante na rede de relações institucionais distribuidoras de serviços públicos aos cidadãos.

A descentralização, a globalização, a busca da eficiência, da equidade e da transparência e a procura de novas respostas para os velhos problemas conduziram à erosão do modelo tradicional de administração pública, jurídico, hierarquizado, altamente centralizado e burocratizado. Esta implosão do modelo tradicional obrigou a reinventar a relação entre o estado e a sociedade, e é neste contexto que emerge a nova governação pública.

Ao contrário do modelo burocrático, que impunha a regulação de processos intraorganizacionais, a nova governação pública obriga à interoperabilidade, à 
programação e gestão das consultas, e à articulação interorganizacional, onde o conflito mais facilmente se pode instalar (Bjur e Caiden, 1978; Law, 1994).

Assim, a teoria da governação pública lança as raízes tanto na ciência política quanto na sociologia das organizações e na teoria da complexidade, reconhecendo que a natureza da gestão pública é atualmente incerta e fragmentada (Haveri, 2006), usufruindo da atual corrente da sociologia que releva os aspetos relacionais e estratégicos da organização à tradicional análise intraorganizacional e sistémica de entrada, transformação e saída (Bilhim, 2008).

Trata-se de um estado plural na diversidade dos seus elementos e de um estado pluralístico na riqueza dos seus processos. Neste contexto, a equidade, a transparência e a eficácia da ação do estado em matéria de políticas públicas são conseguidas através da complexa relação interorganizacional e da qualidade da governação dos processos. A ênfase é posta na sustentabilidade das relações interorganizacionais, onde a confiança, o capital relacional e os contratos relacionais constituem os principais instrumentos de gestão destas redes (Neves, 2010).

\section{O contributo da sociologia das organizações e da economia para a teoria da governação}

Na sociologia das organizações, é na metáfora política e cibernética e na teoria do poder e controlo, onde há uma atitude positiva relativamente à mudança, à inovação, ao ajustamento mútuo e à negociação, que a nova governação pública encontra grande parte das suas bases teóricas. $\mathrm{O}$ estudo das organizações, enquanto sistemas políticos, foi particularmente levado a cabo por autores europeus como Crozier e Friedberg $(1979,2007$; Crozier, 1963, 1987), a quem se deve a introdução de conceitos-chave, como os de "ator social", "zonas de incerteza" e "sistemas de ação concretos".

Para estes autores constitui zonas de incerteza todo e qualquer problema técnico, estrutural ou social com relevância para a organização, e para o qual não existem soluções pré-programadas. É neste contexto que os atores sociais individuais ou institucionais reforçam as suas posições, estabelecendo alianças, coligações ou gerando oposição. A análise organizacional passa a ser análise estratégica. A estratégia opera no interior das organizações, e por ela os objetivos, as estruturas e o próprio estilo de gestão se tornam inteligíveis (Fernandes, 1998; Bilhim, 2008).

Pensar a complexidade é respeitar a tessitura comum, o complexo que ela forma para além de suas partes (Morin, 1975). A complexidade que a administração enfrenta na sua missão exige que as práticas de gestão apontem para uma tessitura de redes complexas de relações que se estabelecem entre as dimensões técnica, política e ética, caraterísticas da administração. Nesta perspetiva, os administradores são profissionais de uma atividade cujo exercício exige a posse e a aplicação de saberes que os habilitam a lidar com as exigências contraditórias e as pressões impostas pela mobilização de recursos, bem como com a pressão dos esforços para manter o seu comportamento dentro dos limites prescritos (Reed, 1989; Dandeker, 1990). 
No mesmo sentido da análise da complexidade vai o contributo de Bourdieu (1997), com os conceitos de habitus como sistema aberto de disposições, submetido constantemente à experiência, ou os de locus e campo, que se revestem de grande significado para esta nova abordagem da gestão de complexas redes de cooperação social de atores individuais e institucionais.

Nesta mesma linha, a teoria das redes sociais (social network theory) sugere que as relações interorganizacionais são caraterizadas por duas propriedades únicas: interdependência e enraizamento (embeddedness - Granovetter, 1985; Neal, 2013). A interdependência sugere que cada organização depende não só das organizações com as quais interage, mas também de todas as outras presentes nos sistemas económicos, políticos e sociais.

O enraizamento social refere-se ao facto de uma organização representada pelos seus atores não poder atuar livremente, estando constrangida pelas expetativas de outras organizações pertencentes à mesma rede (Touraine, 1996). Do mesmo modo, a imobilidade geográfica e a proximidade entre as unidades de governo criam oportunidades para o estabelecimento de uma densa rede de relações firmemente agrupadas, que promovem o capital social, geram confiança e reciprocidade e minimizam o oportunismo (Gulati, 1995; Berardo e Scholz, 2010).

Por outro lado, a economia representa um bom contributo para este problema da cooperação interorganizacional. Assim, a teoria da ação coletiva institucional (ACI) e a sua aplicação ao estudo dos mecanismos de colaboração em redes complexas de cooperação social para resolver dilemas de ação coletiva institucional pode ser muito importante (Feiock, Steinacker e Park, 2009).

O enquadramento teórico da ACI, é influenciado por grande número de teorias desenvolvidas em diversas disciplinas das ciências sociais, nomeadamente a literatura sobre ação coletiva individual, a teoria das economias públicas, a análise dos custos de transação, a teoria das redes sociais e a literatura sobre instrumentos de políticas públicas como fundamentos teóricos da abordagem.

A ACI remonta à literatura sobre a ação coletiva individual para a qual os interesses comuns e os objetivos partilhados podem ser insuficientes para obter uma ação coletiva bem-sucedida (Olson, 1971 [1965]). Para grandes grupos, é mais difícil atingir os interesses coletivos do grupo sem um sistema adequado de incentivos à participação individual. Os custos individuais de participação podem suplantar os benefícios individuais; por isso se impõe a criação de um adequado sistema de incentivos à mobilização dos membros do grupo. O resultado agregado é inferior à quantidade eficiente por causa do free-riding, razão por que parece ser mais difícil a grupos de grande dimensão atingirem os seus objetivos coletivos. A ACI estende esta lógica individual aos atores compósitos definidos pela posição, autoridade e regras de agregação (Ostrom, 2005).

A nova governação pública requer a existência de instituições de governação com a capacidade necessária para expressar, mudar e impor as regras através das quais a produção e o fornecimento de bens e serviços têm lugar (Oakerson e Parks, 2011; V. Ostrom, 1989; E. Ostrom, 2010). A teoria assenta no policentrismo enquanto "processo de tomada de decisão pelo qual vários atores 
independentes interagem para produzir um resultado que é comummente avaliado" (V. Ostrom, Tiebout e Warren, 1961; V. Ostrom, 1971).

\section{Da administração pública tradicional à nova governação pública}

Há dois paradigmas distintos na administração pública: o da Common Law, ou anglo-saxónico, e o da Europa Continental (Bilhim, Pinto e Pereira, 2015). Se os processos de reforma e os respetivos impactos na teoria e na prática da administração pública foram diferentes no paradigma da Common Law, ou seja, nos países anglófonos e nos países da Europa Continental, diferentes também são as bases que nestes dois paradigmas apresenta a teoria da governação (Stillman, 1997).

A administração pública tradicional, nos paradigmas da Common Law e da Europa Continental, dominante desde o século XIX até finais dos anos 70 do século XX, apresenta diferentes caraterísticas (ver quadro 1).

A grande diferença entre estas duas tradições encontra-se na falácia jurídica, à qual se recorreu na Europa Continental, mormente em Portugal, que segue aproximadamente o seguinte raciocínio no pensamento jurídico nacional: são os fins do estado, permanentes ou conjunturais, que determinam o tipo e a feição das funções; ora, são as normas jurídico-públicas que qualificam tais funções como atividades do estado; por isso, as funções do estado dependem das normas e, antes de mais, das constitucionais, o que conduz a que todas as funções do estado sejam funções jurídicas (Miranda, 1990).

Neste silogismo lógico, a falácia encontra-se na frase "ora, são as normas jurídico-públicas que qualificam tais funções como atividades do estado". As normas jurídico-públicas qualificam as funções como atividades do estado, tal como as normas do direito comercial qualificam as funções da empresa. A tradução para uma norma não muda a natureza das funções do estado que foram cometidas pelo povo aos seus representantes como incumbências ou atividades destinadas à solução de problemas comuns.

Quando, nos anos 70 do século XX, se desencadeia a crise no keynesianismo, modelo económico dominante, e acontece a sua substituição pelo modelo neoclássico e da escolha pública, os impactos desta mudança acarretam consequências diferentes para cada um dos dois paradigmas administrativos, por terem as mesmas bases e caraterísticas distintas. Acresce que, com frequência, vemos alguns investigadores portugueses assumir, de forma acrítica e errónea, que a administração pública portuguesa, ou mesmo a da Europa Continental, possui as mesmas caraterísticas da administração anglófona. Ora, da comparação que acabámos de estabelecer resulta claramente que há traços comuns e traços muito distintos, porque cada paradigma lança as suas raízes em terrenos teóricos diferenciados.

Tendo por base estes diferentes pontos de partida quanto à administração pública tradicional, vamos agora analisar o impacto produzidos pelas reformas nos paradigmas da Common Law e da Europa Continental.

Os modelos de reforma que tiveram lugar no paradigma da Common Law nomeadamente na Nova Zelândia, Austrália e Reino Unido - foram promovidos 
Quadro 1 Principais caraterísticas dos dois paradigmas

\begin{tabular}{|c|c|c|}
\hline Caraterísticas & "Common Law" & "Europa Continental" \\
\hline Raízes teóricas & $\begin{array}{l}\text { Construção política baseada no } \\
\text { conceito de sociedade industrial }\end{array}$ & $\begin{array}{l}\text { Construção política baseada } \\
\text { no conceito de estado-nação. }\end{array}$ \\
\hline Relação entre ação e lei & Princípio da ação & Princípio da legalidade \\
\hline Mapeamento mental & Separação entre pensamento e ação & Não há diferença \\
\hline O ciclo das políticas públicas & $\begin{array}{l}\text { Separação entre formulação da } \\
\text { política pública e implementação }\end{array}$ & $\begin{array}{l}\text { Integração do desenho } \\
\text { e da implementação }\end{array}$ \\
\hline $\begin{array}{l}\text { Relação entre eleitos } \\
\text { e "profissionais" }\end{array}$ & $\begin{array}{l}\text { Dicotomia entre política e } \\
\text { administração. Hegemonia dos } \\
\text { políticos no desenho e dos } \\
\text { "profissionais" na implementação das } \\
\text { políticas públicas }\end{array}$ & $\begin{array}{l}\text { Não há diferença; todos são, em } \\
\text { simultâneo, políticos e } \\
\text { administradores. }\end{array}$ \\
\hline $\begin{array}{l}\text { Responsabilidade pelo } \\
\text { serviço/política pública }\end{array}$ & O governo é responsável & $\begin{array}{c}\text { O governo é responsável direto pelas } \\
\text { incumbências do estado que projetam } \\
\text { a ação do poder político }\end{array}$ \\
\hline Critério de sucesso & $\begin{array}{l}\text { Cumprimentos de objetivos } \\
\text { e obtenção de resultados }\end{array}$ & Conformidade \\
\hline Valores orientadores & Mérito & $\begin{array}{c}\text { Obediência aos procedimentos } \\
\text { e normas }\end{array}$ \\
\hline
\end{tabular}

pelo que ficou conhecido como nova gestão pública (NGP) (Hood, 1991), típica dos sistemas de democracia parlamentar, ou seja, do modelo Westminster; nos Estados Unidos, dado o seu caráter federalista e menos centralizado, pelo modelo da "reinvenção da governação" (RG) (Osborne e Gaebler, 1992; Gore, 1996); e, simultaneamente em todos os países de língua inglesa, pelo "novo serviço público" (NSP) (Denhardt e Denhardt, 2003), que tentou evitar a rutura, estabelecendo pontes entre estes novos modelos e a administração pública tradicional.

Quando se comparam estes três modelos verifica-se que apresentam caraterísticas diferenciadas (ver quadro 2).

No paradigma europeu continental os processos de reforma são diferentes e estão marcados pelo "novo estado weberiano" (NEW) (Pollit e Bouckaert, 2004: 99) - "what we see in the Continental European states is a distintive reform model, one we which to call the Neo-Weberian State (NWS)". A Europa Continental não imita o processo de reforma que se iniciara na Common Law, mas, não lhe sendo indiferente, reage então de uma forma singular ao vendaval que se afigurava arrasar a administração pública, caraterizado por Osborne (2006:377) como "it would sweep all before it in its triumphal re-casting of the nature of the discipline in theory and in practice".

Isto significa que, da análise aos processos de reforma dos estados da Europa Continental, se pode verificar que há caraterísticas do velho estado weberiano que são mantidas, e por vezes reforçadas, e caraterísticas novas que assumem um novo papel.

Na Europa é o estado que faz a administração e não o contrário, como aconteceu na América (Stillman, 1997). A Europa Continental encara o estado como o guardião da vontade comum. Para os europeus continentais o interesse público é um constructo que não se confunde com o interesse dos públicos/indivíduos. 
Quadro 2 Síntese das caraterísticas dos três modelos

\begin{tabular}{|c|c|c|c|}
\hline Caraterísticas & NGP & RG & NSP \\
\hline $\begin{array}{l}\text { Valores orientadores } \\
\text { do estado }\end{array}$ & Mérito e eficiência & Mérito & $\begin{array}{l}\text { Ideais do serviço público; } \\
\text { prestação de contas } \\
\text { e responsabilização. }\end{array}$ \\
\hline Raízes teóricas & $\begin{array}{l}\text { Teoria económica da escolha } \\
\text { pública }\end{array}$ & Filosofia da gestão privada & $\begin{array}{l}\text { Teoria da cidadania ativa, } \\
\text { valorização das pessoas }\end{array}$ \\
\hline Estrutura orgânica & $\begin{array}{l}\text { Fragmentação da unidade } \\
\text { do estado centralizado }\end{array}$ & $\begin{array}{c}\text { Focalizada na missão, } \\
\text { descentralizada, voltada } \\
\text { para resultados, de tipo } \\
\text { empresarial }\end{array}$ & $\begin{array}{l}\text { Luta contra a fragmentação, } \\
\text { dimensão mais humanista }\end{array}$ \\
\hline Papel do cidadão & Cliente & A administração pertence-lhe & $\begin{array}{l}\text { Recetor de serviços } \\
\text { e bens públicos }\end{array}$ \\
\hline Papel do estado & $\begin{array}{l}\text { Libertar as forças de } \\
\text { mercado: competição }\end{array}$ & $\begin{array}{c}\text { Promover a concorrência } \\
\text { e a orientação para } \\
\text { o mercado }\end{array}$ & $\begin{array}{l}\text { Atuar democraticamente } \\
\text { e pensar estrategicamente, } \\
\text { servir e não mandar }\end{array}$ \\
\hline Método de pesquisa & Positivista & Positivista & $\begin{array}{l}\text { Métodos da } \\
\text { pós-modernidade, } \\
\text { qualitativos }\end{array}$ \\
\hline
\end{tabular}

Para Hegel, a separação de poderes de Montesquieu é importante, mas é preciso compreender que tal separação não pode passar de um princípio de distribuição de funções, não comprometendo a unidade soberana do estado. É que, para o filósofo, a divisão de poderes é uma desconcentração de funções estatais. Está subjacente no pensamento do autor a imagem de que o estado é um concreto histórico, ser vivo onde há diferenciação de órgão e funções que integram o todo. A separação de poderes incentiva a sua independência, o que, levado ao extremo, poderia significar a dissolução do estado como unidade orgânica, onde a monarquia seria o elemento político desse projeto.

É através da burocracia que o estado se assume como realidade concreta e fornece serviços públicos aos seus membros. A burocracia, para o filósofo, é a concretização da soberania, expressa nos funcionários do estado; ela assume materialmente a existência do estado como realidade concreta por um conjunto de funções e atribuições regulares, que apenas os funcionários podem exercer como representantes e expressão do próprio estado.

Bluntschli, na esteira deste organicismo da teoria política, vai defender que a política é a atividade do estado nas coisas grandes e universais, enquanto a administração é a atividade do estado nas coisas pequenas e individualizadas, constituindo a política a área de intervenção específica do estadista, e a administração a do funcionário. A produção de diretivas políticas não dispensa a cooperação da administração; mas tal facto não transforma a administração em política, ou seja, nem a administração é política nem a política é administração.

$\mathrm{Na}$ Europa Continental a perspetiva jurídica tem sido a abordagem marcante em todos os países do velho continente. A sua ligação está claramente patenteada no facto de se localizar, nas faculdades de direito europeias, uma 
Quadro 3 Comparação entre elementos weberianos e neoweberianos

\begin{tabular}{|c|c|}
\hline Elementos weberianos & Elementos neoweberianos \\
\hline $\begin{array}{l}\text { Reafirmação do papel do estado como principal } \\
\text { facilitador na resolução de problemas tais como } \\
\text { globalização, mudança tecnológica, mudança } \\
\text { demográfica e ameaça ambiental. }\end{array}$ & $\begin{array}{l}\text { Mudança de orientação: focalização na envolvente } \\
\text { externa alinhada com a satisfação das necessidades } \\
\text { e desejos do cidadão, conseguida mais por uma } \\
\text { cultura profissional de qualidade e de serviço do que } \\
\text { pela introdução de mecanismos de mercado. }\end{array}$ \\
\hline $\begin{array}{l}\text { Reafirmação do papel da democracia representativa } \\
\text { (central, regional, local) como elemento de } \\
\text { legitimação do poder }\end{array}$ & $\begin{array}{l}\text { De forma suplementar (não substitutiva) a democracia } \\
\text { representativa é enriquecida por instrumentos } \\
\text { de consulta e de representação direta dos cidadãos } \\
\text { (mais presente ao nível da administração local } \\
\text { e no norte da Europa. }\end{array}$ \\
\hline $\begin{array}{c}\text { Reafirmação da importância do direito administrativo } \\
\text { — adequada aos novos tempos - na preservação } \\
\text { de princípios básicos relativos à relação estado/ } \\
\text { cidadão, nomeadamente quanto à igualdade perante } \\
\text { a lei, à segurança jurídica e ao escrutínio das ações } \\
\text { do estado }\end{array}$ & $\begin{array}{l}\text { Publicação de leis incentivando a meritocracia, } \\
\text { os resultados, mais do que o cumprimento dos } \\
\text { procedimentos, nomeadamente no equilibrio entre } \\
\text { controlo a priori e a posteriori, sem abandonar } \\
\text { totalmente o anterior dos procedimentos }\end{array}$ \\
\hline $\begin{array}{l}\text { Preservação da ideia do serviço público, embora } \\
\text { em novos moldes }\end{array}$ & $\begin{array}{l}\text { Profissionalização do serviço público: o funcionário já } \\
\text { não é apenas um perito na interpretação e aplicação da } \\
\text { lei, mas também um gestor profissional, orientado para } \\
\text { satisfazer as necessidades dos cidadãos/ utentes }\end{array}$ \\
\hline
\end{tabular}

Nota: adaptação (Pollit e Bouckaert, 2004).

cadeira ou uma licenciatura com o nome de ciência administrativa ou ciência de administração.

Por outro lado, o imperativo do direito sobre a ciência da administração revela-se, ainda, no facto de desempenhar um papel importante nesta ciência, já que ocupa um capítulo onde se distingue a ciência da administração do direito administrativo. Este último, encarado como disciplina normativa, fundada sob os métodos da lógica formal, e a ciência da administração vista como disciplina positiva, que tem por objeto a administração tal e qual ela é. Apesar desta separação, em geral admitida, nem por isso a ciência da administração deixa de ser tributária dos esquemas do direito administrativo.

É ainda a partir de critérios de tipo administrativo que se institui o próprio objeto da ciência da administração - ou seja, ela trata da administração pública enquanto titular de um estatuto específico -, e da sujeição a um regime jurídico que se afasta, e muito, do regime de direito comum.

Com a emergência do mercantilismo e do absolutismo régio a administração pública encontra no cameralismo desenvolvido na Prússia nos séculos XVII e XVIII a sua expressão mais fiel. O cameralismo representava uma espécie de "tecnologia administrativa", cujas técnicas e teorias foram desenvolvidas na Europa e sistematizadas entre meados do século XVI e finais do século XVIII, em que o estado foi concebido como entidade coletiva, orgânica e unitária (Small, 2009 [1909]).

Ora, se o impacto da Revolução Francesa se fez sentir de imediato na feitura das leis em Portugal pela ação dos liberais, a sua influência na universidade levou um pouco mais tempo. Para Pedrosa (1908: 8), “data portanto do ano letivo de 1853 
a 1854, na Faculdade de Direito da Universidade de Coimbra, em cadeira própria, o ensino dos princípios de administração e do direito administrativo", seguindo os conteúdos dos Principes d'Administration Publique de Bonnin.

Para a antiga escola clássica, nascida em França no primeiro quartel do século XIX, e daí espalhada por toda a Europa, nomeadamente Portugal, a ciência da administração pública andava associada à ciência jurídica e, em particular, ao direito administrativo.

Se para Bonnin (1812) o direito administrativo bastava por si para dar conhecimento de todas as matérias da administração pública, para Stein o direito administrativo devia ser desterrado e substituído por outras disciplinas - tais como a das finanças, a do exército e a da administração propriamente dita -, por entender que a ideia da administração é dada pela ideia de estado operante.

\section{A nova governação pública}

A nova governação pública está longe de reunir consenso na literatura académica de administração pública, funcionando como guarda-chuva de realidades muito distintas: sinónimo de administração pública e de implementação de políticas públicas; identificada com a nova gestão pública (NGP); tida como conjunto de teorias que trata do declínio da soberania e da fragmentação institucional do estado. Esta nova governação pública surge sob diversas designações - "The New Public Governance" com Osborne (2006), "New Governance" com Rhodes (1997), "The Public Governance" com Skelcher (2005) e Stephen (2006). Sob estes diferentes nomes, deteta-se uma tendência comum de mudança das perspetivas teóricas dominantes nas últimas três décadas do século passado e a emergência de algo novo e diferente relativamente às raízes teóricas, ao foco e ênfase de análise, à natureza do estado, aos mecanismos de gestão e aos valores prosseguidos.

O estudo científico da governação tenta, por um lado, compreender os fatores que estão na base da decisão de colaborar, os benefícios e custos associados, e como a colaboração pode gerar resultados e impactos positivos na sociedade. Mas, por outro lado, as redes de colaboração podem envolver conflitos de interesses e resultados negativos ou desejáveis apenas para uma das partes e prejudiciais para as restantes. Neste ponto, os estudos da governação permitem ajudar formulando hipóteses que ligam conceitos teóricos suscetíveis de ser submetidos ao teste empírico antes de serem generalizadas asserções.

Na Europa Continental, o maior contributo para a teoria da governação tem origem na tradição académica holandesa, que salienta a necessidade de coordenação e responsabilização dos atores que atuam nas redes de governação (Kooiman, 1993; Kickert, Klijn e Koppenjan, 1997). Esta corrente valoriza a componente horizontal das redes, ao contrário das restantes, que salientam a hierarquia e o mercado.

Atualmente as organizações públicas estão confrontadas com o impacto de duas ondas diferentes. As práticas atuais já não correspondem a qualquer modelo do passado mas ainda não se encontram integradas e unificadas numa nova teoria. 
Muita coisa se passou nestes 30 anos após a queda do Muro de Berlim, em 1989: novo paradigma económico, "nova escolha pública"; transformações geopolíticas; globalização; emergência da China e da Índia; impacto das tecnologias de informação em geral.

Os estudos sobre a governação pública contribuíram para a teoria e a prática da administração perderem as suas amarras tradicionais, havendo mesmo, para Lynn, uma bússola que se perdeu. Todavia há quem veja aqui uma oportunidade de a administração se reinventar e encontrar ideias novas para os problemas relativamente aos quais a administração tradicional já não apresentava respostas.

Na perspetiva de Lynn, Laurence, Heinrich e Hill (2000: 235), “a governação diz respeito aos meios para alcançar a direção, o controlo e a coordenação dos indivíduos ou organizações total ou parcialmente autónomos em favor dos interesses para os quais contribuem em conjunto". Isto implica que no conceito de governação haja elementos separados, mas inter-relacionados, que incluem elementos organizacionais, financeiros, estruturas programáticas, leis, regulamentos administrativos, recursos disponíveis, normas e regras institucionalizadas. Por outras palavras, o sucesso da governação depende da capacidade do governo e do setor público em implicar/comprometer todos os parceiros pertinentes numa tomada de decisão consensual destinada à promoção da ação coletiva em busca de fins comuns (Ansell e Gash, 2008).

Acontece que o conceito de governação opera a três níveis: institucional, organizacional e técnico. Ao nível institucional, a governança procura compreender a formação, adoção e implementação da política pública; ao nível organizacional ou de gestão, compreende as questões da hierarquia entre departamentos, agências independentes e entidades do terceiro setor, concentrando-se ainda nos incentivos, no poder administrativo, medidas da realização; ao nível técnico, foca-se na envolvente específica de atuação organizacional, nomeadamente nas questões ligadas ao profissionalismo, competência técnica, motivação, transparência, performance, meritocracia, eficiência, liderança (Bilhim, 2013a).

Para Peters e Pierre (1998), há quatro elementos presentes na governação: domínio das redes de relação; perda, pelo estado, do controlo direto que antes possuía; fraca separação entre recursos públicos e privados; uso de múltiplos instrumentos na solução dos problemas. A teoria da governação pública (TGP) enfatiza a dispersão do poder, postura contrária ao modelo hierárquico, linear, integrado, típico da produção em massa; salienta a necessidade de coordenação das entidades que desenvolvem o processo de políticas públicas; baseia-se na criação de fortes redes de relação e parcerias; coloca na troca de recursos entre parceiros a razão de ser das redes; ressalta a confiança e a estabilidade contratual como critérios de sucesso; faz sobressair a importância das organizações sociais na solução de problemas sociais, a que nem o estado nem o mercado dão resposta por si sós ou conjuntamente.

Referidos os quatro elementos básicos que na perspetiva de Peters e Pierre (1998) distinguem os estudos da governação da NGP, importa agora salientar os pontos que possam ter em comum, até porque nalgumas definições do termo governação este é sinónimo daquele. De acordo com os mesmos autores, encontram-se igualmente elementos diferenciadores entre NGP e governação. 
Ambos os modelos reduzem o papel tradicional e as responsabilidades dos políticos eleitos, ambos os modelos continuam a ter um papel significativo na fixação de objetivos de desenvolvimento de redes de relações a longo prazo, mas já não são os atores dominantes. Há uma transferência de poder dos atores tradicionais para novos atores de tipo empresarial numa rede de relações. Esta mudança não deixa de levantar sérios problemas de prestação de contas e responsabilização. Os dirigentes da administração ou os políticos já não podem ser responsabilizados nos termos tradicionais, colocando-se então o problema de saber quem é responsável pela execução de uma determinada política.

Outro aspeto comum radica no pressuposto de que existe um distanciamento entre governo e cidadãos que está na base da ineficiência e da falta de cortesia. Embora a globalização tenha obrigado o setor privado a ser mais eficiente, através da redução de custo de produção e da redução das estruturas, e mais sensível às necessidades dos clientes, adotando sofisticados instrumentos de gestão, o setor público está isolado deste movimento por causa do monopólio do estado sobre a produção do serviço público. Assim, ambos os modelos apresentam a competição como o instrumento adequado à obtenção de maior eficiência, corrigindo as ineficiências inerentes às burocracias e aumentando a capacidade de resposta ao cidadão.

Acresce que ambos os modelos estão orientados para resultados, gestão por objetivos e controlo dos outputs, em contraste com a tradição administrativa que controlava os inputs. Por outro lado, ambos os modelos simpatizam com o princípio da RG de "dirigir e não remar", cunhado por Osborne e Gaebler (1992), em que dirigir significa fixar os grandes objetivos de política.

\section{A nova governação pública e a meritocracia}

A meritocracia é tão antiga quanto o mandarinato, não sendo de estranhar, nos tempos modernos, que esta orientação para o mérito remonte aos primórdios da ciência da administração, tendo muito cedo aparecido nos EUA, a pautar as relações entre a ciência da administração e a gestão privada (Woodrow Wilson, 1887) e, posteriormente, nos princípios da "administração científica" advogados por Frederick Taylor (1947 [1911]).

Woodrow Wilson (1887) defende a separação entre políticos e burocratas, afirmando, consequentemente, que estes devem ocupar as posições de poder no interior da estrutura organizacional de acordo com o seu mérito. Já no século XX Max Weber (1978) atribuiu particular ênfase à meritocracia, ao referir, na caraterização da burocracia formal, que a seleção dos trabalhadores se faz com base nas qualificações técnicas e que as mesmas podem ser testadas através de exames ou diplomas em que se certifique a posse da formação técnica dos candidatos.

Acontece que a difusão do princípio do mérito nos EUA anda associada ao Pendleton Civil Service Act (16 de janeiro de 1883). Esta lei fundadora do sistema americano de mérito inspirou-se no sistema britânico, que é um sistema de gestão e organização de recursos humanos da administração pública baseado (i) na competitive 
examination, concurso e hierarquização de candidatos, (ii) na segurança relativa de emprego e (iii) na neutralidade política. Nos EUA o sistema de gestão de recursos humanos baseado no mérito, no setor público, apenas se generalizou nos anos 40 do século passado (Ruhil e Camões, 2003). No entanto, "The merit system, perfected and made permanent by the Pendleton Act, increased efficiency elsewhere" (Hoogenboom 1958: 316).

Na Europa Continental, os organicistas alemães sempre se preocuparam com a eficiência da administração pública e os próprios franceses, embora fundamentalmente focados no direito administrativo, não a desprezaram: "Napoleon was obsessed by the cost-efficiency of his administration and the Prussian bureaucracy was famous and feared for its forceful effectiveness" (Kickert, 1997: 750).

Todavia, a sua importância foi revisitada pela nova gestão pública (NGP), cuja sigla passou a lugar-comum com o artigo de Christopher Hood (1991) intitulado "A public management for all seasons?". Neste artigo o autor expõe as novas tendências da gestão pública que recaem na definição de padrões de desempenho mensuráveis, no controlo sobre os resultados e na utilização de técnicas de gestão privada no setor público. As práticas de responsabilização de tipo processual ou legal tendem a ser substituídas ou, no mínimo, complementadas por outras orientadas para o desempenho (Pierre e Peters, 2000). A utilização sistemática destas práticas a partir do início da década de 1980 justifica o nome atribuído ao modelo da NGP.

Por força das crises económica e fiscal dos anos 70, o modelo da NGP recupera a ênfase na eficiência, neutralidade política e preparação técnica para defender a utilização de técnicas de gestão privada no âmbito do setor público. O primado do cliente, a flexibilização da contratação e compensação de funcionários, a contenção dos custos e o controlo do desempenho pelos resultados tornaram-se objetivos centrais da atuação dos governos locais influenciados por esta corrente (Carvalho, 2007; Mozzicafredo, 2011; Rocha, 2001).

Acontece que a seleção com base no mérito tem sido valorizada e aceite ao longo dos tempos, como sinal de modernidade, garantia ética, baluarte contra a corrupção e garantia de imparcialidade na gestão das pessoas no setor público.

Para a sociologia contemporânea, a meritocracia corresponde a um sistema em que as posições sociais são preenchidas com base no mérito individual e não em virtude de critérios como a riqueza, o sexo, a origem social ou a cor do partido político em que se milita (Bilhim: 2008). Contudo, para o paradigma administrativo da Europa Continental, focalizado na interpretação e aplicação da lei, e não na eficiência, esta mudança implica uma transformação cultural.

O século XX legou-nos uma teoria e práticas de administração pública robustas e resilientes à mudança. Todavia, a resiliência precisa de se adaptar, ser contingencial às novas circunstâncias e ao imprevisto.

Parece existir entre os académicos, que ensinam, e os práticos, que trabalham nas organizações públicas, uma espécie de crença generalizada sobre uma administração pública ideal, onde a corrupção seria totalmente derrotada e o mérito constituiria a regra na ocupação de todos os cargos e funções na estrutura do estado.

Ora se é certo que Max Weber, na esteira dos autores organicistas alemães, estabelecia a meritocracia como consequência da evolução social, não é menos certo 
que a nova gestão pública (NGP), desde a década de 80 do século passado, combatendo o modelo burocrático weberiano de organização do estado e da administração pública, coloca a urgência da introdução de sistemas meritocráticos como um dos pontos essenciais da sua cartilha.

Com efeito, nas quatro últimas décadas assistiu-se a uma crítica generalizada ao desempenho das organizações públicas, acusadas de fidelidade ao modelo weberiano e, consequentemente, de estarem em contraciclo com a evolução social, impondo-se, por isso, a modernização administrativa cujo ponto central seria a introdução do mérito (Bilhim, 2013b).

Fica, porém, claro que esta questão do mérito tem acompanhando, no Ocidente, a administração pública, pelo menos desde o liberalismo, e que a cultura meritocrática leva tempo a instalar-se. Já Conover referia que nos Estados Unidos, nos anos 20, apenas um terço dos funcionários estava no sistema público com base no mérito e que estes se encontravam assimetricamente representados nos diversos tipos de administração, local, estadual e federal (Canover, 1925), ou seja, a busca da eficiência baseada no mérito tem sido o motor dos processos de mudança nos modelos de administração e políticas públicas e continua a sê-lo agora com a nova governação pública, se bem que num novo contexto.

\section{Conclusão}

No paradigma da Common Law a administração pública tradicional foi varrida por três modelos - NGP, RG e NSP -, apelando cada um deles a uma administração pública mais parecida com a empresarial, mais orientada para o mercado e para o cliente, no pressuposto de que seria fácil a transposição das teorias e das técnicas da gestão dos negócios para o setor público.

O grande argumento contra esta facilidade na transposição e imitação do privado pelo público encontra-se, nomeadamente, nas diferenças de natureza, envolvente e caraterísticas organizacionais destes setores (Allison, 1992). A administração pública tem de lidar mais com padrões e valores do que com critérios empresariais, tais como legalidade e legitimidade, justiça social e igualdade de direitos. O que não significa desprezo pelos critérios de eficiência e eficácia, ou a rejeição do mérito como um valor comum a ambos os setores.

Os três modelos de reforma anglo-saxónicos e o NEW no paradigma europeu continental fizeram implodir a administração pública tradicional, tal como fora conhecida durante décadas, separando provisão e produção em matéria de políticas públicas, o que teve como consequência a emergência de uma plêiade de entidades prestadoras de bens e serviços públicos. Ora, é para satisfazer a necessidade de gerir esta rede de prestadores que a nova governação pública se assume como o modelo a ter em conta no futuro já presente da administração e políticas públicas.

Esta nova realidade implica o posicionamento de novas questões de pesquisa e a necessidade de revisitar os autores clássicos e atuais da área da sociologia, que tenham trabalhado as redes sociais e as questões da colaboração e do poder. Por isso, no Centro de Administração e Políticas Públicas (CAPP), a nossa linha de 
pesquisa desenvolve uma agenda de investigação que avalia empiricamente o impacto da perda de autonomia institucional, pela adoção de instrumentos de cooperação para a obtenção de resultados mais positivos para os cidadãos ao nível infraestadual, estadual e supraestadual.

Para o futuro, em termos teóricos alinham-se as seguintes questões: Em que medida a teoria da governação pública rompe ou está em linha com a administração pública tradicional e os modelos da Common Law e da Europa Continental? Que competências-chave de gestão em contexto interorganizacional devem ser desenvolvidas? Quais os impactos da passagem de estrutura simples para a gestão complexa de parcerias? Como avaliar o mérito num modelo que funciona baseado em redes de cooperação social?

Do ponto de vista teórico será de toda a importância aprofundar a relação entre interesse público e valor público. Os sistemas de gestão pública defendem o interesse público ou acrescentam valor público a ser distribuído pelos cidadãos? Estará o conceito jurídico de interesse público em linha com os novos modelos dinâmicos de gestão pública, mormente com a nova governação pública? Por fim, com o estertor do conceito de jus imperium, instrumento crítico do modelo europeu continental, nascem as redes sociais e com elas a oportunidade de a sociologia (que, ao longo do tempo, tem analisado as dinâmicas sociais facilitadoras e inibidoras da cooperação humana e institucional) poder dar um valioso contributo à teoria da administração e das políticas públicas.

\section{Referências bibliográficas}

Aligica, Paul D., e Vlad Tarko (2012), “Polycentricity: from Polanyi to Ostrom, and beyond", Governance, 25 (2), pp. 237-262.

Allison, G. T. (1992), "Public and private management: are they fundamentally alike in all unimportant aspects?", em G. M. Shafritz e A. C. Hyde, Classics of Public Administration, Belmont, CA, Wordsworth, pp. 457-474.

Ansell, Chris, e Alison Gash (2008), "Collaborative governance in theory and practice", Journal of Public Administration Research and Theory, 18, pp. 543-571.

Berardo, Ramiro, e J. Scholz (2010), “Self-organizing policy networks: risk, partner selection, and cooperation in estuaries", American Journal of Political Science, 54 (3), pp. 632-649.

Bilhim, João (2000), “Gerir a administração pública como uma empresa”, em Reforma do Estado, Lisboa, ISCSP.

Bilhim, João (2008), Teoria Organizacional. Estruturas e Pessoas, Lisboa, ISCSP.

Bilhim, João (2013a), Ciência da Administração, Lisboa, ISCSP.

Bilhim, João (2013b), “O papel dos gestores na mudança cultural da administração central do Estado: o caso da meritocracia", Passagens, Revista Internacional de História Política e Cultura Jurídica, 5 (2), pp. 205-227.

Bilhim, João, Ricardo Pinto, e Miguel Pereira (2015), “Paradigmas administrativos, ética e intervenção do Estado na economia: o caso de Portugal", Revista Digital de Derecho Administrativo, 14 (segundo semestre), pp. 91-125. 
Bjur W. E., e G. E. Caiden (1978), “On reforming institutional bureaucracies”, International Review of Administration Sciences, 44, pp. 359-365.

Bonnin J. C. (1812), Principes d'Administration Publique, Paris, Renaudière, Imprimeur-Libraire (3. a edição).

Bourdieu, Pierre (1997), Razões Práticas. Sobre a Teoria da Acção, Oeiras, Celta Editora.

Bovaird, Tony (2007), “Beyond engagement and participation: user and community coproduction of public services", Public Administration Review, 67 (5), pp. 846-860.

Carvalho, Elisabete (2007), "Políticas de reforma administrativa em Portugal" em Elisabete Carvalho, working paper no âmbito do projeto "Administração Pública e Competitividade Numa Perspectiva Comparada", Lisboa, ISCSP, CAPP.

Conover, Milton (1925), "Merit systems of civil service in the States", The American Political Science Review, (19 (3), pp. 544-560.

Crozier, M. (1963), Le Phénomène Bureaucratique, Paris, Editions du Seuil.

Crozier, M. (1987), Etat Moderne, Etat Modeste, Paris, Editions du Seuil.

Crozier, Michel, e Erhard Friedberg (1979), “Sociologie des organisations et fonctionnement des entreprises", Revue Française de Sociologie, 20 (3), pp. 491-493.

Crozier, Michel, e Erhard Friedberg (2007), L'Acteur et le Système, Paris, Editions du Seuil.

Dandeker, C. (1990), Surveillance, Power and Modernity, Cambridge, Polity Press.

Denhardt, J., e R. Denhardt (2003), The New Public Service. Serving not Steering, Londres, M. E. Sharp.

Feiock, Richard, Annette Steinacker, e Hyung-Jun Park (2009), “Institutional collective action and economic development joint ventures", Public Administration Review, 69 (2), pp. 256-270.

Fernandes, A. Teixeira (1998), Os Fenómenos Políticos. Sociologia do Poder, Porto, Edições Afrontamento.

Gore, Albert (1996), Reinvenção da Administração Pública, Lisboa, Quetzal.

Granovetter, Mark (1985), "Economic action and social structure”, American Journal of Sociology, 91 (3), pp. 481-510.

Gulati, Ranjay (1995), “Does familiarity breed trust? The implications of repeated ties for contractual choice in alliances", Academy of Management Journal, 38 (1), pp. 85-112.

Haveri (2006), "Complexity in local government change: limits to rational reforming", Public Management Review, 8 (10), pp. 31-46.

Hood, C. (1991), “A public management for all seasons?”, Public Administration, 69, pp. 3-19.

Hoogenboom, Ari (1958), "Pendleton Act and the civil service", The American Historical Review, 64 (2), pp. 301-318.

Kettl, Donald (2000), The Global Public Administration Revolution. A Report on the Transformation of Governance, Washington, DC, Brookings Institution.

Kettl, Donald (2002), The Transformation of Governance, Baltimore, The Johns Hopkins University Press.

Kickert, Walter J. M. (1997), "Public governance in the Netherlands: an alternative to Anglo-American managerialism", Public Administration, 75, pp. 731-752.

Kickert, Walter J. M., E.-H. Klijn, e Joop F. M. Koppenjan (orgs.) (1997), Managing Complex Networks. Strategies for the Public Sector, Londres, Sage Publications.

Kooiman, Jan (org.) (1993), Modern Governance. New Government-Society Interactions, Londres, Sage Publications. 
Larry, D. Terry (2005), "The thinning of administrative institutions in the hollow state", Administration \& Society, 37 (4), pp. 426-444.

Law, John (1994), Organizing Modernity, Oxford, Blackwell Publishers.

Lynn Jr., E. Laurence, Carolyn J. Heinrich, e Carolyn Hill (2000), “Studying governance and public management: challenges and prospects", Journal of Public Administration Research and Theory, 10 (2), pp. 233-262.

Milward, H. Brinton, e Keith G. Provan (2000), “Governing the hollow state”, Journal of Public Administration Research and Theory, 10 (2), pp. 359-379.

Miranda, Jorge (1990), Funções, Órgãos e Actos do Estado, Lisboa, Faculdade de Direito da Universidade de Lisboa.

Morin, Edgar (1975), O Paradigma Perdido. A Natureza Humana, Mem Martins, Edições Europa América.

Mozzicafreddo, Juan (org.) (2011), “Contextos e etapas da reforma na administração pública", em Juan Mozzicafreddo e João Salis Gomes (orgs.), Projetos de Inovação na Gestão Pública, Lisboa, Mundos Sociais.

Neal, Zachary P. (2013), The Connected City. How Networks Are Shaping the Modern Metropolis, Nova Iorque, Routledge.

Neves, Arminda (2010), Governação Pública em Rede, Lisboa, Edições Sílabo.

Oakerson, Ronald J., e Roger B. Parks (2011), “The study of local public economies: multi-organizational, multi-level institutional analysis and development", Policy Studies Journal, 39 (1), pp. 147-167.

Olson, Mancur (1971 [1965]), The Logic of Collective Action. Public Goods and the Theory of Groups, Cambridge, MA, Harvard University Press.

Osborne, D. (2006), The New Public Governance? Emerging Perspectives on the Theory and Practice of Public Governance, Londres, Routledge \& Francis Group.

Osborne, D., e T. Gaebler (1992), Reinventing Government, Reading, MA, Addison-Wesley Publishing.

Ostrom, Elinor (2005), Understanding Institutional Diversity, Princeton, NJ, Princeton University Press.

Ostrom, Elinor (2010), “Beyond markets and states: polycentric governance of complex economic systems", American Economic Review, 100 (June), pp. 641-672.

Ostrom, Vincent (1971), "Public choice: a different approach to the study of public administration", Public Administration Review, 31, pp. 203-216.

Ostrom, Vincent (1989), The Intellectual Crisis in American Public Administration, Tuscaloosa, AL, University of Alabama Press.

Ostrom, Vincent, Charles Tiebout, e Robert Warren (1961), “The organization of governments in metropolitan areas", American Political Science Review, 55 (4), pp. 831-842.

Pedrosa (1908), Curso de Ciência da Administração e de Direito Administrativo, Coimbra, Imprensa da Universidade.

Peters, B. Guy (1993), “Managing the hollow state” em K. Eliassen e J. Kooiman (orgs.), Managing Public Organizations, Londres, Sage Publications, pp. 46-57.

Peters, Guy, e Jon Pierre (1998), “Governance without government? Rethinking public administration", Journal of Public Administration Research and Theory, 8, pp. 227-243.

Pierre, Jon, e Guy Peters (2000), Governance, Politics, and the State, Nova Iorque, St. Martin's Press. 
Pollit, C., e G. Bouckaert (2004), Public Management Reform. A Comparative Analysis, Oxford, Oxford University Press.

Reed, Michael (1989), The Sociology of Management, Londres, Harvester Wheatsheaf. Rhodes, R. A. W. (1994), “The hollowing out of the state”, Political Quarterly [edição eletrónica] 65 (2), pp. 138-151.

Rhodes, R. A. W. (1997), Understanding Governance, Buckingham, Open University Press.

Rhodes, R. A. W. (2000), "Governance and public administration”, em Jon Pierre (org.), Debating Governance, Oxford, Oxford University Press, pp. 54-90.

Rocha, J. A. O. (2001), Gestão Pública e Modernização Administrativa, Oeiras, Instituto Nacional de Administração.

Ruhil, Anirudt, e Pedro Camões (2003), “What lies beneath: the political roots of state merit systems", Journal of Public Administration Research and Theory, 13 (1), pp. 27-42.

Skelcher, C. (2005), “The public governance of collaborative spaces", Public Administration, 83, pp. 573-596.

Small, A. (2009 [1909]), The Cameralists. The Pioneers of German Social Polity, Nova Iorque, General Books.

Stephen, P. O. (2006), “The New Public Governance?”, Public Management Review, 8, pp. 377-387.

Stillman, R. (1997), “American vs. European public administration", Public Administration Review, 5 (4), pp. 332-338.

Tavares, António, e Luís Mamede (2011), “The effects of institutional design in program performance: Promoting sustainable cities in Portugal", Management of Environmental Quality - An International Journal, 22 (3), pp. 330-343.

Taylor, F. (1947 [1911]), Scientific Management, Nova Iorque, Harper \& Row. Touraine, Alain (1996), O Retorno do Actor, Lisboa, Instituto Piaget.

Weber, Max (1978), Economy and Society, Berkley, University of California Press.

Wilson, Woodrow (1887) "The study of administration", Political Science Quarterly, 2, pp. 197-222.

João Abreu de Faria Bilhim (corresponding author). Investigador responsável pelo projeto "Do Governo à Governação", Centro de Administração e Políticas Públicas, ISCSP-UL, Lisboa. E-mail: bilhim@iscsp.ulisboa.pt

Receção: 25 de maio de 2016 Aprovação: 24 de novembro de 2016 
